\title{
Ultrasound Assisted Cascade Extraction of Oil, Vitamin E, and Saccharides from Roselle (Hibiscus Sabdariffa L.) Seeds
}

\author{
Bang Anh Le,* Kenji OKITSU, ${ }^{* * \dagger}$ Kiyoshi Imamura, ${ }^{* *}$ Norimichi TaKenaKa, ${ }^{* *}$ and Yasuaki MaEdA** \\ *Graduate School of Engineering, Osaka Prefecture University, Sakai 599-8531, Japan \\ **Graduate School of Humanity and Sustainable System Sciences, Osaka Prefecture University, Sakai 599-8531, \\ Japan
}

\begin{abstract}
Roselle seeds, a waste biomass of the roselle calyx processing industry, were utilized to recover valuable compounds of oil, vitamin E, and water-soluble saccharides. Firstly, ultrasound-assisted extraction (UAE) and conventional stirring extraction were conducted for saccharide extraction, and the advantage of UAE was confirmed. Secondly, oil, vitamin E, and saccharides extracted from Vietnamese roselle seeds by UAE were analyzed for the first time. Oil of tri-, di-, and mono-glycerides, fatty acids of linoleic-, oleic-, palmitic-, and stearic-acids, vitamin E of $\gamma$ - and $\alpha$-tocopherol, and saccharides of sucrose, raffinose, stachyose, etc. were identified, and the amounts of these components were compared with those in other country's roselle seeds. Thirdly, cascade extraction of oil, vitamin E, and saccharides by UAE was investigated with solvents of hexane, hexane:ethyl acetate binary solvent, and water. The results indicated that the order of using solvents was very important for high and selective extraction: the best order to recover oil (almost 100\%), vitamin E (95.7\%), and saccharides (86.2\%) was hexane, and then water.
\end{abstract}

Keywords Vitamin E, saccharide, oil, roselle seed, ultrasound, cascade extraction, hydrolysis

(Received March 4, 2020; Accepted April 14, 2020; Advance Publication Released Online by J-STAGE April 24, 2020)

\section{Introduction}

Roselle (Hibiscus Sabdariffa L.) seeds are an agricultural waste originating in a food processing of roselle calyces, which have been proven to be of pharmaceutical value ${ }^{1}$ and applied in food and medicine industries, ${ }^{2}$ especially the beverage industry. ${ }^{3}$ Roselle is native from India, Malaysia, and Africa, and it has been widely cultivated in the tropics and subtropics of both hemispheres. ${ }^{4}$

Previous studies have showed that roselle seeds are a rich source of oil, ${ }^{5,6}$ tocopherols, ${ }^{7}$ saccharides, proteins, and fibers. ${ }^{8,9}$ Indeed, roselle seeds contain about $14.6-21.6 \mathrm{wt} \%$ of oil, ${ }^{5,6}$ which could be used as a feedstock to produce biofuel, ${ }^{10}$ or could be considered to be edible oil. ${ }^{11-13}$ However, it was also confirmed that the roselle seed oil contained a $2.9 \%$ total concentration of sterculic (C19) and malvalic (C18) acids, which are known to be toxic and co-carcinogenic. ${ }^{14}$ Therefore, to utilize the roselle seed oil as edible oil, it is mandatory to confirm whether the oil is safe or not for human consumption. The use of the roselle seed oil in the cosmetics industry is also promising due to its high $(1.55 \%)$ unsaponifiable matters content. $^{9}$ The oil also contains a variety of bioactive phytochemicals, namely polyphenols and phenolic acids, ${ }^{6}$ nutritional attributes ${ }^{8,9}$ phytosterols, ${ }^{7}$ and amino acids. ${ }^{15}$

In addition, roselle seeds are a rich source of tocopherols $(2000 \mathrm{mg} / \mathrm{kg}),{ }^{7}$ which are called vitamin E. Vitamin E is a group of natural antioxidants which showed promising roles in

† To whom correspondence should be addressed.

E-mail: okitsu@mtr.osakafu-u.ac.jp preventing and curing Alzheimer's disease, cancer, ${ }^{16,17}$ cardiovascular disease, ${ }^{18,19}$ inhibiting platelet aggregation and intra-arterial thrombus formation, ${ }^{20}$ and delaying ageing. ${ }^{21,22}$ It has an important role in protecting cells from oxidative stress through donating electrons to free radicals to neutralize them. ${ }^{19}$ The human body cannot synthesize vitamin E; it must be obtained from nutritional sources, such as vegetable and seed oils. ${ }^{23-25}$ Therefore, vitamin $\mathrm{E}$ is regarded as an important industrial constituent, such as an additive of foods ${ }^{26}$ and drugs. ${ }^{27}$

In addition to oil and vitamin $\mathrm{E}$, roselle seeds contain a large amount of carbohydrate $(21.3-26.6 \mathrm{wt} \%){ }^{8}{ }^{8} 9$ Plant saccharides, namely polysaccharides, have been believed to have specific biological activities, such as anticancer activity, antibacterial activity, and immune-enhancing effects. They are also used for drug design, ${ }^{28}$ because they can scavenge free radicals for the prevention of oxidative damage. ${ }^{29,30}$ Antioxidant effects of polysaccharides originating in many kinds of plants, such as Artemisia sphaerocephala Krasch seeds, ${ }^{31}$ Amomum villosum seeds, ${ }^{32}$ and Ganoderma lucidum, ${ }^{29}$ were reported and saccharides extracted from roselle seeds acted as free-radical scavengers. $^{33}$ In addition, polysaccharides can be utilized to produce bioethanol. ${ }^{34,35}$

There are many methods for the extraction of valuable compounds in plants, which contain microwave-assisted extraction, enzyme-assisted extraction, ultrasonic-assisted extraction (UAE), Soxlhet extraction, and supercritical carbon dioxide fluid extraction. ${ }^{32,36-38}$ UAE has several prominent advantages including reasonably high extraction yields, moderate solvent requirements, a relatively short extraction time, ${ }^{37}$ and retaining high antioxidant activity of the extract. ${ }^{32}$

In this study, firstly, the extraction of saccharides from roselle 
seeds was investigated by UAE, and the results were compared with conventional stirring extraction (SE). Secondly, the components of oil, vitamin E, and saccharides in roselle seeds cultivated in Vietnam were extracted by UAE and characterized for the first time. The results were compared with those in other country's roselle seeds. Thirdly, cascade extraction by UAE for saccharides, vitamin E, and oil was investigated with extraction solvents of water, hexane:ethyl acetate binary solvent, and hexane, respectively. In addition, the effects of the extraction solvent order were investigated to recover valuable components with high yields and selectivity.

\section{Experimental}

\section{Materials}

Roselle seeds were collected from roselle calyces harvested from Vietnam. They were packed in paper bags and stored in a dark and dry place at room temperature until use. The seeds were homogenized using an electrical mill (Wonder Blender WB-1). After screening with a sieve (20 mesh, JIS standard), particles with less than $0.85 \mathrm{~mm}$ size were used for experiments. The water content of homogenized seeds was $4.7 \mathrm{wt} \%$. Mono-, di-, triolein, methyl linoleate, and methyl oleate were purchased from Sigma Aldrich (Tokyo, Japan). Hexane, ethyl acetate, ethanol, methyl stearate, methyl palmitate, ascorbic acid, potassium hydroxide $(\mathrm{KOH})$, phenol, sulfuric acid $\left(\mathrm{H}_{2} \mathrm{SO}_{4}\right)$, and sodium sulfate $\left(\mathrm{Na}_{2} \mathrm{SO}_{4}\right)$ were of analytic grade, and were purchased from Wako Pure Chem. (Osaka, Japan). $\alpha-, \beta-, \gamma-$, and $\delta$-tocopherols and their corresponding tocotrienols were purchased from Supelco (Bellefonte, PA, USA). Deionized purified water was used in this study.

\section{Comparison between ultrasound-assisted extraction (UAE) and} stirring extraction (SE) for saccharide extraction

UAE was performed with an ultrasound cleaning bath (AS ONE, ASU-10, $40 \mathrm{kHz}$, total nominal power: $500 \mathrm{~W}$, Japan). The ultrasound power injected indirectly in the sample solution in a glass flask was $0.67 \mathrm{~W}$, which was measured by a calorimetric method. ${ }^{39}$ The extraction conditions were as follows: the ratio of the sample seeds $(\mathrm{g})$ to the solvent volume $(\mathrm{mL}), 1: 10(\mathrm{~g}: \mathrm{mL})$; the extraction temperature, $30^{\circ} \mathrm{C}$; and the duration, $30 \mathrm{~min}$. For a comparison, SE was performed by stirring at $300 \mathrm{rpm}$ using a magnetic stirrer, Big Squid (Ika, Japan) under the same extraction condition as the UAE.

\section{Vitamin E extraction}

First, $0.20 \mathrm{~g}$ of ascorbic acid, $14 \mathrm{~mL}$ of ethanol:water $(5: 2 \mathrm{v} / \mathrm{v}), 1.0 \mathrm{~mL}$ of $\mathrm{KOH}(0.50 \mathrm{~g} / \mathrm{mL})$, and $10 \mathrm{~mL}$ of hexane:ethyl acetate $(8: 2 \mathrm{v} / \mathrm{v})$ were added into a $50-\mathrm{mL}$ glass test tube containing $1.0 \mathrm{~g}$ of a homogenized sample. After sealing with a cap, the test tube was placed at the center of an ultrasound cleaning bath. The UAE was conducted for $20 \mathrm{~min}$. The residue was separated from the liquid by centrifugation at $3000 \mathrm{rpm}$ for $10 \mathrm{~min}$, and then the liquid was collected into a separatory funnel $(100 \mathrm{~mL})$. The resultant residue was re-extracted two more times by $7 \mathrm{~mL}$ and then $5 \mathrm{~mL}$ of hexane:ethyl acetate $(8: 2 \mathrm{v} / \mathrm{v})$ with the cleaning bath for $10 \mathrm{~min}$, as above. The resultant solutions of 3-time extraction were combined and separated to the upper phase and the lower phase. The upper phase was washed 2 times by $5 \mathrm{~mL}$ of water, and then the remaining water was removed by $\mathrm{Na}_{2} \mathrm{SO}_{4}$. After that, the upper phase was moved to a volumetric flask $(25 \mathrm{~mL})$ and filled up by hexane:ethyl acetate $(8: 2 \mathrm{v} / \mathrm{v})$ for analyzing tocopherols by HPLC. Vitamin E consists of a chromanol ring bound to a hydrophobic chain. Figure S1 (Supporting Information) shows their chemical structures.

\section{Oil extraction}

First, $20 \mathrm{~mL}$ of hexane was added to a $50-\mathrm{mL}$ glass test tube containing $1.0 \mathrm{~g}$ of a homogenized sample. The duration of UAE was $30 \mathrm{~min}$. After extraction, the residue was separated from the liquid by filtration using a filter paper (Whatman \#1 HP7 9NA), and then the supernatant was collected. This process was repeated three times. The resultant solutions of 3-time extraction were combined and then concentrated by a rotary evaporator under a reduced pressure. The oil content of the sample was measured by a gravimetric method.

\section{Saccharide extraction}

First, $10 \mathrm{~mL}$ of water was added to a $50-\mathrm{mL}$ glass test tube containing $1.0 \mathrm{~g}$ of a homogenized sample. The duration of UAE was $30 \mathrm{~min}$. After extraction, the residue was separated by centrifugation and filtration, as described above. This process was repeated 2 times with $10 \mathrm{~mL}$ and then $5 \mathrm{~mL}$ of water. The resultant solutions of 3-time extraction were combined and then moved to a $25-\mathrm{mL}$ volumetric flask and filled up with water for spectrophotometric analysis of carbohydrates.

\section{Oil analysis after vitamin E extraction}

The oil content in an organic phase obtained by a binary solvent was determined by HPLC, while the oil content remaining in solid phase, which was dried at $105^{\circ} \mathrm{C}$ for $5 \mathrm{~h}$, was re-extracted by hexane, and then determined by HPLC. The difference between the maximum and measured contents of oil (in upper phase of binary extraction and in solid phase) was attributed to saponification.

\section{Analytical procedure for vitamin E, oil, and saccharide}

The components and concentrations of tocopherols and oil were determined using an HPLC system. The fatty acid components of oil were characterized by a method reported by Thanh et al. ${ }^{40}$ The concentration of saccharides, which contain mono-, di-, tri-, and polysaccharides, was analyzed using a phenol-sulfuric method reported by Dubois et al. ${ }^{41}$ The components of saccharides were characterized using a HPLC system. The detail analysis conditions for vitamin E, oil, saccharide are described in lines $12-70$ in Supporting Information.

\section{Results and Discussion}

\section{Effects of UAE on yield of saccharide components}

The UAE method was used for the extraction of saccharides, and the results were compared with those of the SE method. Water was used for an extraction solvent. The results are shown in Fig. 1. It was confirmed that roselle seeds contain fructose, glucose, sucrose, raffinose, and stachyose: the concentrations of the main saccharides of sucrose, raffinose, and stachyose were $20.0,17.9$, and $11.0 \mathrm{mg} / \mathrm{g}$, respectively. The yield of the total saccharides in seeds by the UAE method was found to be $53.4 \pm 2.0 \mathrm{mg} / \mathrm{g}$, which was higher by $13.1 \%$ than that $(47.2 \pm 1.5 \mathrm{mg} / \mathrm{g})$ by the SE method $(p<0.05)$. It has been reported that strong physical effects, such as shockwaves and micro-jets, are generated by 20 - $40 \mathrm{kHz}$ ultrasound irradiation, ${ }^{42,43}$ and promote the disruption of cell tissues and the interpenetration of the solvent into the plant cells to dissolve saccharides. ${ }^{44-46}$ Because of these phenomena, saccharides in the seed matrix 


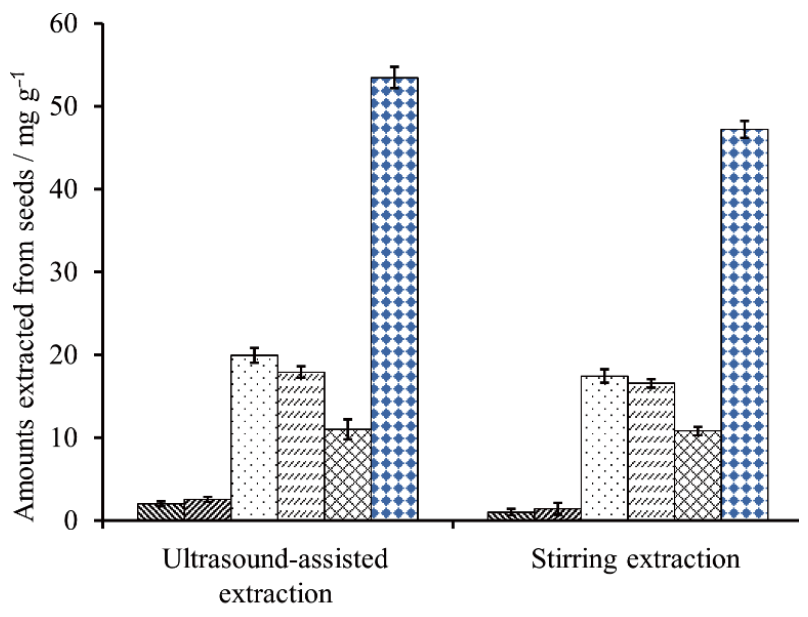

$\mathbb{N}$ Frucose $\square$ Glucose $\boxminus$ Sucrose $\otimes$ Raffinose $\otimes$ Stachyose $\otimes$ Total

Fig. 1 Comparison of the extraction methods of stirring extraction and ultrasound-assisted extraction for saccharides. Extraction condition: temperature, $30^{\circ} \mathrm{C}$; ratio of solid (homogenized sample) to water, 1:10 (g:mL); extraction duration, $30 \mathrm{~min}$; stirring rate of SE, $300 \mathrm{rpm}$; values, mean $\pm \mathrm{SD}(n=3)$; frequency of UAE, $40 \mathrm{kHz}$; F, fructose; G, glucose; S, sucrose; R, raffinose; St, stachyose; Total, sum of F, G, S, R, and St.

Table 1 Characteristics of oil and fatty acid in roselle seed

\begin{tabular}{|c|c|c|c|}
\hline & \multicolumn{3}{|c|}{ Growing location of roselle seed } \\
\hline & $\begin{array}{l}\text { Vietnam } \\
\text { (This study) }\end{array}$ & Malaysia $^{5}$ & Spain $^{7}$ \\
\hline Oil content, wt $\%$ & $18.0 \pm 0.5$ & $14.6 \pm 1.5$ & $19.0 \pm 0.3$ \\
\hline Triglycerides (TGs), wt \% & $86.6 \pm 0.7$ & $\mathrm{ND}^{\mathrm{c}}$ & $\mathrm{ND}^{\mathrm{c}}$ \\
\hline Diglycerides (DGs), wt \% & $8.8 \pm 1.0$ & $\mathrm{ND}^{\mathrm{c}}$ & $\mathrm{ND}^{\mathrm{c}}$ \\
\hline Monoglycerides (MGs), wt $\%^{\mathrm{a}}$ & $4.6 \pm 0.3$ & $\mathrm{ND}^{\mathrm{c}}$ & $\mathrm{ND}^{\mathrm{c}}$ \\
\hline Palmitic acid (C16:0), wt $\%^{\mathrm{b}}$ & $18.5 \pm 0.7$ & $21.4 \pm 0.4$ & $20.0 \pm 0.7$ \\
\hline Stearic acid (C18:0), wt $\%^{\mathrm{b}}$ & $3.7 \pm 0.1$ & $5.0 \pm 0.2$ & $5.3 \pm 0.1$ \\
\hline Oleic acid (C18:1), wt $\%^{\mathrm{b}}$ & $32.9 \pm 0.6$ & $26.2 \pm 0.5$ & $28.7 \pm 0.7$ \\
\hline Linoleic acid (C18:2), wt $\%^{\mathrm{b}}$ & $40.0 \pm 1.1$ & $39.4 \pm 0.3$ & $40.1 \pm 0.8$ \\
\hline Other fatty acids, wt $\%^{\mathrm{b}}$ & $3.0 \pm 0.7$ & 8.0 & 5.9 \\
\hline
\end{tabular}

a. Relative percent composition of glyceride in roselle seed oil. b. Relative percent composition of fatty acid in roselle seed oil. c. Not determined.

were released to water more effectively. Based on these effects, UAE was used for the extraction of all components in this study.

Characteristics of oil, vitamin E, and saccharides in roselle seeds Since the components and concentration of Vietnamese roselle seeds have not yet been measured so far, we tried to analyze those at first. Oil in roselle seeds was recovered by UAE with hexane. The characteristics of oil in Vietnamese roselle seeds are given in Table 1. The oil content in roselle seeds in Vietnam was confirmed to be $18.0 \%$. This value is the middle between those of roselle seeds in Malaysia (14.6\%) and in Spain (19.0\%). The main component of roselle seed oil was triglycerides, which contained $86.6 \pm 0.7 \mathrm{wt} \%$, while diglycerides and monoglycerides were $8.8 \pm 1.0$ and $4.6 \pm 0.3 \mathrm{wt} \%$, respectively. These are not investigated for roselle seeds in Malaysia and Spain.

It was also confirmed that roselle seed oil consisted of saturated $(22.2 \%)$ and unsaturated $(72.9 \%)$ fatty acids, and the
Table 2 Characteristics of vitamin $\mathrm{E}$ in roselle seed

\begin{tabular}{lcccc}
\hline & \multicolumn{4}{c}{ Growing location of roselle seed } \\
\cline { 2 - 5 } & $\begin{array}{c}\text { Vietnam } \\
\text { (This study) }\end{array}$ & Egypt $^{11}$ & Spain $^{7}$ & Malaysia $^{5}$ \\
\hline$\alpha$-Tocopherol, \% & 28.3 & 28.6 & 25.0 & 4.5 \\
$\beta$-Tocopherol, \% & 2.7 & 0.2 & $\mathrm{ND}^{\mathrm{a}}$ & 3.9 \\
$\gamma$-Tocopherol, \% & 68.2 & 70.2 & 74.5 & 86.0 \\
$\delta$-Tocopherol, \% & 0.8 & 0.9 & 0.5 & 5.6 \\
Total tocopherols $/ \mu \mathrm{g} \mathrm{g}^{-1}$ & $120.5 \pm 0.2$ & $192.4 \pm 0.5$ & $380.2 \pm 7.4$ & 119.9 \\
\hline
\end{tabular}

a. Not determined.

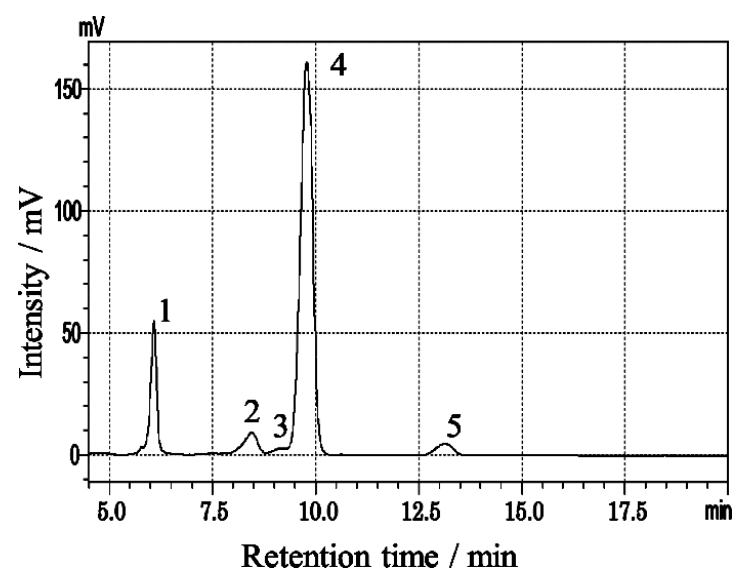

Fig. 2 HPLC chromatogram of tocolpherols extracted in the upper phase from roselle seeds. (Legend: 1, $\alpha$-tocopherol; 2, unknown compound; $3, \beta$-tocopherol; 4, $\gamma$-tocopherol; $5, \delta$-tocopherol).

proportion of the unsaturated fatty acids was greater than that of the saturated fatty acids. The major unsaturated fatty acids were linoleic $(40.0 \%)$ and oleic $(32.9 \%)$ acids, while the saturated fatty acids were palmitic (18.5\%) and stearic (3.7\%) acids. These results almost agreed with the composition of roselle seed oil cultivated in Malaysia and Spain (Table 1). The high content of the unsaturated fatty acids explained why roselle seed oil shows high antioxidant properties. ${ }^{7}$

For vitamin $\mathrm{E}$ which contains isomers as tocopherols $(\alpha-, \beta-$, $\gamma-$, and $\delta$-T) and the corresponding tocotrienols and tocomonoenols, its characteristics in Vietnamese roselle seeds are given in Table 2, where the results of other countries are listed for comparison. The total tocopherol content (vitamin E) was confirmed to be $120.5 \mu \mathrm{g} / \mathrm{g}$ of seeds. This content attested that vitamin $\mathrm{E}$ in seeds in Vietnam was comparable with $119.9 \mu \mathrm{g} / \mathrm{g}$ of seeds in Malaysia. However, Al-Okbi et al. and Mohamed et al. reported that the vitamin E content in seeds in Egypt and Spain, respectively, were $192.4 \mu \mathrm{g} / \mathrm{g}^{11}$ and $380.2 \mu \mathrm{g} / \mathrm{g}^{7}$. These differences would be because of cultivating locations and climates.

The present study indicated that all of the isomers of tocopherols $(\alpha-, \beta-, \gamma-$, and $\delta$-T) were detected by using HPLC, while no peak of tocotrienols and tocomontrienols was observed, as can be seen in Fig. 2. It was confirmed that $\gamma-\mathrm{T}(68.2 \%)$ was the most abundant form in Vietnamese seeds, which was more than twice of $\alpha$-T $(28.3 \%)$, while $\beta$-T and $\delta$-T were only detected with small amounts of 2.7 and $0.8 \%$, respectively. Similar results concerning tocopherol components have been reported in Egypt and Spain (Table 2). 


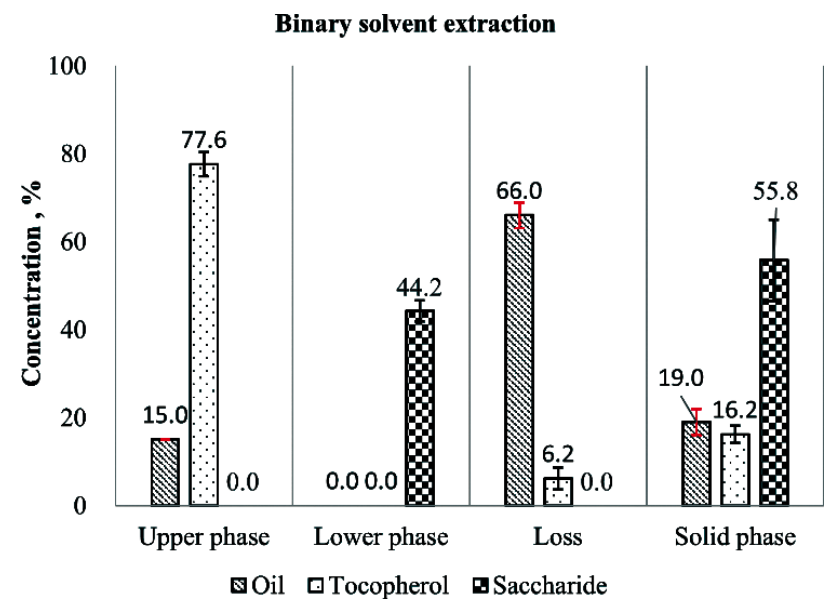

Fig. 3 Fates of oil, tocopherol, and saccharide after extraction by binary solvent (hexane:ethyl acetate 80:20 v/v).

The large amount of $\gamma$-T and $\alpha$-T contained in roselle seeds could play specific roles within the cells of seeds: auto-oxidation of unsaturated fatty acids, which reached $72.9 \%$ in roselle seed oil, could be prevented by $\gamma-\mathrm{T}^{47}$ The functional differences of $\gamma$-T and $\alpha$-T are because of their different physical properties and chemical reactivity against free radicals. ${ }^{48,49}$ Besides, $\gamma$-T and $\alpha$-T play many roles in the regulatory functions in the live cells. $^{50,51}$ To our knowledge, the specific functions of $\beta$-T and $\delta$-T in plants have not yet been clearly confirmed.

Oil recovery by hexane and fate of tocopherols and water-soluble saccharides during oil extraction

When hexane was used as an extraction solvent by UAE, almost $100 \%$ oil $(180 \mathrm{mg} / \mathrm{g})$ and $95.7 \%$ total tocopherol $(115.3 \mu \mathrm{g} / \mathrm{g})$ of roselle seeds were able to be recovered in the hexane phase, while saccharides were remained in the solid phase; it was clear that large amounts of oil and tocopherols were simultaneously extracted by hexane. The results also showed that the content of tocopherols in oil of Vietnamese roselle seeds was $66.9 \mathrm{mg} / 100 \mathrm{~g}$ oil which was less than 82.1 , 96.2, and $200.1 \mathrm{mg} / 100 \mathrm{~g}$ oil in Malaysia, Egypt, and Spain, respectively. (The calculation equation for the tocopherol content in oil is shown in Sect. 2 in Supporting Information). The difference would be because of the geographical location, mode of cultivation, extraction method, and solvent used.

Tocopherol recovery by binary solvent extraction and the fate of oil and water-soluble saccharides during tocopherol extraction

It has been reported that tocopherols could be effectively extracted by a binary solvent with KOH. ${ }^{52}$ Therefore, the same binary solvent was used in this study. The results obtained by UAE are shown in Fig. 3. In the upper phase consisting of hexane and ethyl acetate $(80: 20 \mathrm{v} / \mathrm{v}), 27.0 \mathrm{mg} / \mathrm{g}$ of oil $(15.0 \%)$ and $93.5 \mu \mathrm{g} / \mathrm{g}$ of tocopherols $(77.6 \%)$ were extracted. In the lower phase consisting of water and ethanol, $27.9 \mathrm{mg} / \mathrm{g}$ of saccharides $(44.2 \%)$ was extracted. A significant amount of oil (85.0\%), saccharides (55.8\%), and tocopherols (22.4\%) was lost and/or remained in the seeds (solid phase). No detectable data was indicated as " 0.0 ".

To confirm how amount of oil was saponified by $\mathrm{KOH}$, the losses of oil were evaluated as described in the experimental section. It was confirmed that $66.0 \%$ of oil was lost by saponification. In addition, the formation of soap also induced losses of tocopherols. By analyzing tocopherols in the solid phase, it was confirmed that $6.2 \%$ of tocopherols was lost during the saponification of oil. Although the extraction efficiency (77.6\%) of tocopherols obtained by a binary solvent extraction was lower than that by hexane extraction $(95.7 \%)$, the selectivity of tocopherol extraction by binary solvent was higher than that by hexane; the concentration of tocopherols in $100 \mathrm{~g}$ oil by binary solvent extraction was $346.1 \mathrm{mg}$, which was much larger than $64.1 \mathrm{mg}$ by hexane extraction. (The calculation equation is shown in Sect. 2 in Supporting Information.)

\section{Cascade extraction with water, binary solvent and hexane}

To recover saccharides, tocopherols, and oil with a high yield and selectivity, the effects of the solvent order used in cascade extraction were investigated by the UAE method, as follows: case A, the extraction was performed firstly by water, and then by binary solvent, and finally by hexane; case B, water, hexane, and binary solvent; case $\mathrm{C}$, binary solvent, water, and hexane; case D, binary solvent, hexane, and water; case E, hexane, water, and binary solvent; case F, hexane, binary solvent, and water. Based on the results of above sections, the main components extracted by water, binary solvent, and hexane could be considered as saccharides, tocopherols, and oil, respectively. The results of cascade extraction using different solvent orders are shown in Fig. 4. The sum of the lost by saponification and the unextracted components was plotted as "loss and solid phase" in Fig. 4.

\section{For cases of water used firstly (case A, B)}

In the cases of A and B, $90.4 \%$ of saccharides was extracted by water, while only $7.5-13.1 \%$ of oil and $11.9-12.9 \%$ of tocopherols were recovered by hexane and binary solvent, respectively. The extraction of tocopherols (case A) or oil (case B) met an obstacle because water molecules could constitute a membrane covering seed particles to prevent organic solvents (hexane or binary solvent of hexane and ethyl acetate) contacting with seed particles. Therefore, for these cases, the solid phase would have to be dried before the following extractions. It is clear from Figs. 4A and 4B that large amounts of oil and tocopherols remained as "loss and solid phase". This is a disadvantage in the cases of A and B. However, it should be noted that an advantage of these cases was to be able to recover saccharides selectively by water, a green and cheap solvent.

\section{For cases of a binary solvent used firstly (case C, D)}

For cases $\mathrm{C}$ and D, $77.6 \%$ of tocopherols was able to be recovered by a binary solvent (Figs. $4 \mathrm{C}$ and $4 \mathrm{D}$ ). After that, the extraction of hexane to recover oil was insignificant because $66.0 \%$ of oil was saponified during binary solvent extraction, as described in the result of Fig. 3. From Fig. 3, 19.0\% of oil and $55.8 \%$ of saccharides remained in the solid phase. From Fig. 4, some of saccharides could be recovered by water, while the other part of saccharides was recovered in the lower phase of binary extraction (Fig. 3). From these results, it was clear that a large amount of oil lost by saponification was a disadvantage of cases $\mathrm{C}$ and D. However, for tocopherols, a binary solvent is a solvent that is more selective than hexane. Taking into account the deviation in the amount of tocopherols (more valuable components than oil and saccharides), case $\mathrm{C}$ can be considered to be better than case $\mathrm{D}$.

\section{For cases of hexane used firstly (cases $E, F$ )}

For case E, $100 \%$ of oil and $95.7 \%$ of tocopherols were recovered by hexane (Fig. 4E), and then $86.2 \%$ of saccharides was recovered by water. Only small amounts of these compounds remained in "loss and solid phase". Since it was 

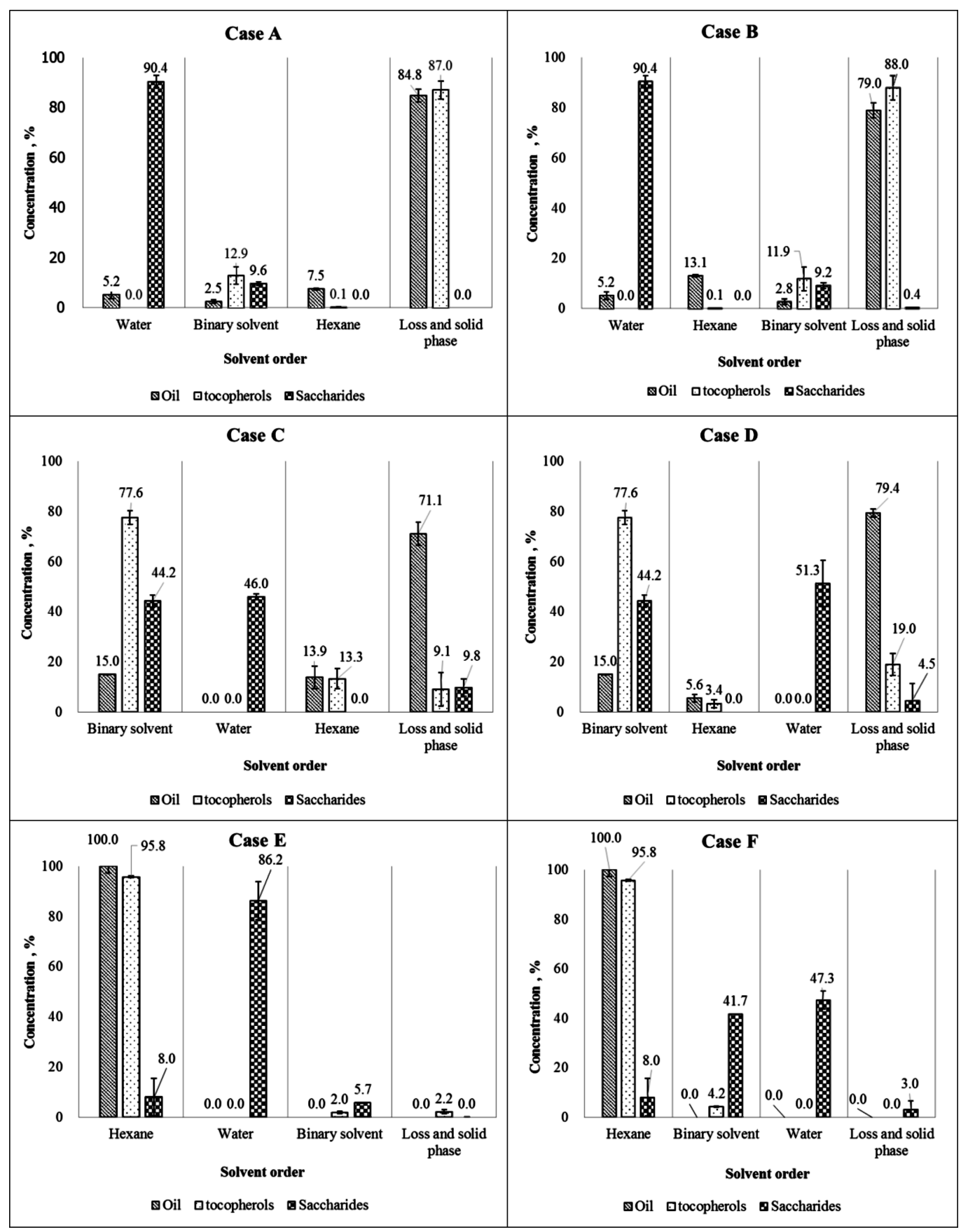

Fig. 4 Effect of the extraction solvent order on the recovery efficiency of oil, tocopherols, saccharides. The extraction order: case A, water, binary solvent, and hexane; case B, water, hexane, and binary solvent; case $\mathrm{C}$, binary solvent, water, and hexane; case $\mathrm{D}$, binary solvent, hexane, and water; case $\mathrm{E}$, hexane, water, and binary solvent; case F, hexane, binary solvent, and water. Note: The sum of the loss by saponification and components not extracted by all solvents are plotted as "loss and solid phase".

clear that almost all tocopherols were recovered by hexane, the extraction by a binary solvent in case $\mathrm{E}$ would be unnecessary. Even in case $\mathrm{F}$, the extraction by a binary solvent would be insignificant for tocopherol (Fig. 4F). The objective components in cases $\mathrm{E}$ and $\mathrm{F}$ that remained were only a small amount in "loss and solid phase" with about $0.0-3.0 \%$ of saccharides and $0.0-2.2 \%$ of tocopherols. Besides, $41.7 \%$ of saccharides (case F) was transferred to the lower phase in binary solvent extraction. The refinement of saccharides in this case must be considered carefully: the refinement of saccharides is an obstacle because saccharides are contained in a binary solvent with high concentration of alkali. To avoid this obstacle, the extraction of tocopherols (step 2 of case F) should be skipped; case E should be chosen and the extraction of tocopherols (final step of case E) is not needed because only a small amount of tocopherols remains in solid phase. It was suggested, in the cases of A and B, that water molecules covering seed particles prevent organic solvents contacting with seed particles, however, this phenomenon could not be observed in the opposite solvent order. From the results in shown Fig. 4, it is concluded that case $\mathrm{E}$ is the best solvent order for the extraction of oil, tocopherols, and saccharides with high yields. 


\section{Conclusions}

The yield of saccharides with ultrasound-assisted extraction (UAE) was larger than that with stirring extraction. The saccharide contents with UAE were confirmed to be sucrose $20.0 \mathrm{mg} / \mathrm{g}$, raffinose $17.9 \mathrm{mg} / \mathrm{g}$, and stachyose $11.0 \mathrm{mg} / \mathrm{g}$. It was also confirmed that Vietnamese roselle seeds contained $18.0 \mathrm{wt} \%$ oil, which consisted of $86.6 \%$ triglycerides, $8.8 \%$ diglycerides, and $4.6 \%$ monoglycerides. These glycerides consisted of $40.0 \%$ linoleic, $32.9 \%$ oleic, $18.5 \%$ palmitic, and $3.7 \%$ stearic acids. The vitamin E content in roselle seeds was $120.5 \mu \mathrm{g} / \mathrm{g}$, which contained of $68.2,28.3,2.7$, and $0.8 \%$ of $\gamma-$, $\alpha-, \beta-$, and $\delta$-tocopherols, respectively. Oil, tocopherols, and saccharides could not be recovered simultaneously in separated solvents of hexane, hexane:ethyl acetate $(8: 2 \mathrm{v} / \mathrm{v})$, and water, respectively. Hexane:ethyl acetate $(8: 2 \mathrm{v} / \mathrm{v})$, which extracted $77.6 \%$ tocopherols, could recover tocopherols more selectively than hexane. Water, a green and cheap solvent, could recover 90.4\% saccharides. If water was used firstly in cascade extraction, it was suggested that the solid phase had to be dried before the following extractions. It was confirmed that the optimum extraction order to recover these components with high yields was the order of hexane and water. The present results could be utilized for the recovery of various types of useful components from inedible plant seeds in the future.

\section{Acknowledgements}

The current study was financially supported by the Science and Technology Research Partnership for Sustainable Development (SATREPS, Project: Multi-beneficial Measure for the Mitigation of Climate Change by the Integrated Utilization of Biomass Energy in Vietnam and Indochina countries), JST-JICA.

\section{Supporting Information}

The details of the experimental procedures and preliminary studies for the extraction of saccharides and enzymatic hydrolysis of saccharides during extraction are described. This material is available free of charge on the Web at http://www. jsac.or.jp/analsci/.

\section{References}

1. K. R. Christian, M. G. Nair, and J. C. Jackson, J. Food Compost. Anal., 2006, 19, 778.

2. I. Da-Costa-Rocha, B. Bonnlaender, H. Sievers, I. Pischel, and M. Heinrich, Food Chem., 2014, 165, 424.

3. M. K. Bolade, I. B. Oluwalana, and O. Ojo, World J. Agric. Sci., 2009, 5, 126.

4. J. F. Morton, "Fruits of Warm Climates", published by Julia F. Morton, 2004, Miami, FL, USA.

5. T. El-Adawy and A. Khalil, J. Agric. Food Chem., 1994, 42, 1896.

6. K. L. Nyam, C. P. Tan, O. M. Lai, K. Long, and Y. B. Che Man, LWT_Food Sci. Technol., 2009, 42, 1396.

7. R. Mohamed, J. Fernández, M. Pineda, and M. Aguilar, J. Food Sci., 2007, 72, S207.

8. H. Al-Wandawi, K. Al-Shaikhly, and M. Abdul-Rahman, J. Agric. Food Chem., 1984, 32, 510.

9. J. M. Nzikou and L. Matos, Curr. Res. J. Biol. Sci., 2011, 3,
141.

10. E. G. Shay, Biomass Bioenergy, 1993, 4, 227.

11. S. Y. Al-Okbi, A. G. Abdel-Razek, S. E. Mohammed, and M. E. S. Ottai, J. Biol. Sci., 2017, 17, 267.

12. B. M. Atta and K. Imaizumi, J. Oleo Sci., 2002, 51, 457.

13. A. A. Eltayeib and A. A. Elaziz, J. Sci. Innov. Res., 2014, 3, 578.

14. C. Rukmini, M. Vijayaraghavan, and G. P. Tulpule, J. Am. Oil Chem. Soc., 1982, 59, 415.

15. K. I. E. Hainida, I. Amin, H. Normah, and N. Mohd-Esa, Food Chem., 2008, 111, 906.

16. Y. Amakura, M. Yoshimura, S. Yamakami, and T. Yoshida, Phytochem. Lett., 2013, 6, 302.

17. P. Pajak, R. Socha, D. Gałkowska, J. Roznowski, and T. Fortuna, Food Chem., 2014, 143, 300.

18. E. Gimeno, E. Calero, A. I. Castellote, R. M. LamuelaRaventós, M. C. De La Torre, and M. C. López-Sabater, J. Chromatogr., A, 2000, 881, 255.

19. F. Puoci, G. Cirillo, M. Curcio, F. Iemma, U. G. Spizzirri, and N. Picci, Anal. Chim. Acta, 2007, 593, 164.

20. T. Saldeen, D. Li, and J. L. Mehta, J. Am. Coll. Cardiol., 1999, 34, 1208.

21. B. N. Ames, Toxicol. Lett., 1998, 102-103, 5.

22. T. Finkel and N. J. Holbrook, Nature, 2000, 408, 239.

23. J. Frank, X. Wei, D. Chin, C. Schrader, G. P. Eckert, and G. Rimbach, Age. Res. Rev., 2012, 11, 163.

24. A. Pyka and J. Sliwiok, J. Chromatogr., A, 2001, 935, 71.

25. M. S. Beldean-Galea, C. Horga, and M. V. Coman, Cent. Eur. J. Chem., 2010, 8, 1110.

26. A. Azzi and A. Stocker, Progress in Lipid Res., 2000, 39, 231.

27. P. M. Bramley, I. Elmadfa, A. Kafatos, F. J. Kelly, Y. Manios, H. E. Roxborough, W. Schuch, P. J. A. Sheehy, and K-H. Wagner, J. Sci. Food Agric., 2000, 80, 913.

28. H. Luo, F. Wang, Y. Bai, T. Chen, and W. Zheng, Colloids Surf., B, 2012, 94, 304.

29. C. Xiaoping, C. Yan, L. Shuibing, C. Youguo, L. Jianyun, and L. Lanping, Carbohydr. Polym., 2009, 77, 389.

30. C. Wang, Y. Chen, M. Hu, J. Ding, C. Xu, and R. Wang, Int. J. Biol. Macromol., 2012, 50, 534.

31. Q. Zheng, D. Ren, N. Yang, and X. Yang, Int. J. Biol. Macromol., 2016, 91, 856.

32. Y. Yan, X. Li, M. Wan, J. Chen, S. Li, M. Cao, and D. Zhang, Carbohydr. Polym., 2015, 117, 632.

33. N. Mohd-Esa, F. S. Hern, A. Ismail, and C. L. Yee, Food Chem., 2010, 122, 1055.

34. C. Piccolo and F. Bezzo, Biomass Bioenergy, 2009, 33, 478.

35. C. N. Hamelinck, G. Van Hooijdonk, and A. P. C. Faaij, Biomass Bioenergy, 2005, 28, 384.

36. A. B. Le, A. Yagura, K. Okitsu, K. Imamura, and N. Takenaka, Jpn. J. Appl. Phys., 2018, 57, 7S1.

37. Y. H. Wong, H. W. Lau, C. P. Tan, K. Long, and K. L. Nyam, Sci. World J., 2014, Article ID 789346, http://dx.doi. org/10.1155/2014/789346.

38. K. W. Chan and M. Ismail, Food Chem., 2009, 114, 970.

39. T. Kimura, T. Sakamoto, J. Leveque, H. Sohmiya, M. Fujita, S. Ikeda, and T. Ando, Ultrason. Sonochem., 1996, 3, S157.

40. L. T. Thanh, K. Okitsu, Y. Sadanaga, N. Takenaka, Y. Maeda, and H. Bandow, Bioresour. Technol., 2010, 101, 639.

41. M. Dubois, K. A. Gilles, J. K. Hamilton, P. A. Rebers, and F. Smith, Anal. Chem., 1956, 28, 350.

42. M. Ashokkumar, Ultrason. Sonochem., 2015, 25, 17.

43. K. Okitsu, Y. Yoshioka, and S. Tanabe, Bunseki Kagaku, 2006, 55, 567. 
44. S. Anvar, J. Food Lipids, 2009, 16, 465.

45. C. Porto, E. Da, Porretto, and D. Decorti, Ultrason. Sonochem., 2013, 20, 1076.

46. Z. Zhang, L. Wang, D. Li, S. Jiao, X. Dong, and Z. Mao, Sep. Purif. Technol., 2008, 62, 192.

47. S. Munné-Bosch and L. Alegre, Planta, 2002, 214, 608.

48. V. Chandra, J. Jasti, P. Kaur, C. Betzel, A. Srinivasan, and T. P. Singh, J. Mol. Biol., 2002, 320, 215.

49. R. Ricciarelli, J. M. Zingg, and A. Azzi, Biol. Chem., 2002,
$383,457$.

50. M. M. Delgado-Zamarreño, M. Bustamante-Rangel, A. Sánchez-Pérez, and J. Hernández-Méndez, J. Chromatogr., A, 2001, 935, 77.

51. J. Parcerisa, I. Casals, J. Boatella, R. Codony, and M. Rafecas, J. Chromatogr., A, 2000, 881, 149.

52. H. T. Truong, P. D. Luu, K. Imamura, T. Matsubara, H. Takahashi, N. Takenaka, L. Van Boi, and Y. Maeda, J. Agric. Food Chem., 2017, 65, 4897. 